\title{
Prototyping Phase of the High Heat Flux Scraper Element of Wendelstein 7-X
}

\author{
J. Boscary ${ }^{\mathrm{a}}$, H. Greuner ${ }^{\mathrm{a}}$, G. Ehrke ${ }^{\mathrm{c}}$, B. Böswirth ${ }^{\mathrm{a}}$, Z. Wang ${ }^{\mathrm{a}}$, E. Clark ${ }^{\mathrm{d}}$, A. Lumsdaine ${ }^{\mathrm{b}}$, J. Tretter ${ }^{\mathrm{a}}$, \\ D. McGinnis ${ }^{\mathrm{b}}$, J. Lore ${ }^{\mathrm{b}}$, K. Ekici ${ }^{\mathrm{d}}$ \\ ${ }^{a}$ Max Planck Institute for Plasma Physics, Garching, Germany \\ ${ }^{b}$ Oak Ridge National Laboratory, Oak Ridge, Tennessee, USA National Laboratory \\ ${ }^{c}$ Max Planck Institute for Plasma Physics, Greifswald, Germany \\ ${ }^{d}$ University of Tennessee, Knoxville
}

\begin{abstract}
The water-cooled high heat flux scraper element aims to reduce excessive heat loads on the target element ends of the actively cooled divertor of Wendelstein 7-X. Its purpose is to intercept some of the plasma fluxes both upstream and downstream before they reach the divertor surface. The scraper element has 24 identical plasma facing components (PFCs) divided into 6 modules. One module has 4 PFCs hydraulically connected in series by 2 water boxes. A PFC, $247 \mathrm{~mm}$ long and $28 \mathrm{~mm}$ wide, has 13 monoblocks made of CFC NB31 bonded by hot isostatic pressing onto a CuCrZr cooling tube equipped with a copper twisted tape. 4 full-scale prototypes of PFCs have been successfully tested in the GLADIS facility up to $20 \mathrm{MW} / \mathrm{m}^{2}$. The difference observed between measured and calculated surface temperatures is probably due to the inhomogeneity of CFC properties. The design of the water box prototypes has been detailed to allow the junction between the cooling pipe of the PFCs and the water boxes by internal orbital welding. The prototypes are presently under fabrication.
\end{abstract}

Keywords: Stellarator; Wendelstein 7-X; Plasma Facing Component; Divertor; Monoblock

\section{Introduction}

The actively water-cooled divertor of the stellarator Wendelstein 7-X (W7-X) is scheduled to start operation in 2019 to enable stationary plasma with a pulse length of up to 30 minutes with $10 \mathrm{MW}$ cw (continuous wave) input power and peak power with additional heating systems of up to $24 \mathrm{MW}$ for $10 \mathrm{~s}$ [1]. This operation phase will be preceded by two intermediate stages: the starting operation phase with an inertially cooled limiter made of graphite blocks for short plasma duration $<1 \mathrm{~s}$ with up to 2 MW power in 2015 shortly followed by the installation of an inertially cooled divertor [2] designed for a plasma duration of 5-10 s with up to $8 \mathrm{MW}$ input power.

Simulations of certain plasma scenarios performed for the preparation of the W7-X long pulse operation revealed that the evolution of the bootstrap current, which has a time constant of 30-40 s, may generate convective heat flux towards the ends of the divertor target elements. The calculated values exceed the experimentally qualified technological limit of $5 \mathrm{MW} / \mathrm{m}^{2}$ at these locations [3].

An additional component, the so-called "scraper element", has been proposed to reduce the heat loads at these sensitive locations by intercepting some of the particle fluxes both upstream and downstream before they reach the divertor surfaces. The description of the physics calculation to determine its positioning and shape with respect to the discrete helical divertor can be found in [4]. This approach will be possibly validated with the installation and operation of an inertially cooled scraper element made of fine grain graphite blocks during the operation phase of the inertially cooled divertor [5].

For the long pulse operation a water-cooled scraper element is required. The purpose of the prototyping phase is the experimental validation of the design and selected technologies to prepare a possible production and operation of the water-cooled scraper element in W7-X.

The scraper element has 24 identical plasma facing components (PFCs) supported by a base plate, 3 connection legs to the plasma vessel and two feeding manifolds, one for the inlet and one for the outlet. The toroidal and poloidal length of the scraper element are 692 and $360 \mathrm{~mm}$, respectively. The 24 PFCs are divided into 6 sets of 4 PFCs. Each set is defined as a scraper module. The prototyping phase focuses on the fabrication and testing of the PFCs and the water boxes that connect 4 PFCs in a module.

\section{Full-scale PFC prototype}

Calculations showed that the expected maximal localized heat load on the scraper element may reach 20 $\mathrm{MW} / \mathrm{m}^{2}$. CFC monoblock prototypes have been successfully tested up to $20 \mathrm{MW} / \mathrm{m}^{2}$ in the frame of the development activities for the ITER divertor [6]. To reduce development activities, the selected design for the PFCs is based on the monoblock design. The fabrication of the PFC prototypes was awarded to the Austrian company Plansee. 8 full-scale prototypes have been produced and delivered in 2015 (Fig. 1).

The monoblocks made of CFC NB31 have been prepared by active metal casting (AMC®) with an 
AMC® copper layer of $0.4 \mathrm{~mm}$. This material was taken from one batch used for the W7-X divertor production. Each PFC has 13 monoblocks for a total length of 247 $\mathrm{mm}$. The cooling tube made of CuCrZr has an inner diameter of $12 \mathrm{~mm}$ and a thickness of $1.5 \mathrm{~mm}$. The CFC thickness between the loaded surface and the AMC® interlayer is $6 \mathrm{~mm}$. The monoblocks are bonded onto the cooling tube by hot isostatic pressing at $\sim 900^{\circ} \mathrm{C}$. The mechanical properties of the CuCrZr material are recovered afterwards by appropriate heat treatment: $970^{\circ} \mathrm{C}$ for 1 hour followed by $475^{\circ} \mathrm{C}$ for 3 hours. The bonds between the monoblocks and the cooling tube have been systematically inspected by thermography in the ARGUS facility by Plansee [7]. All elements fulfilled the specification.
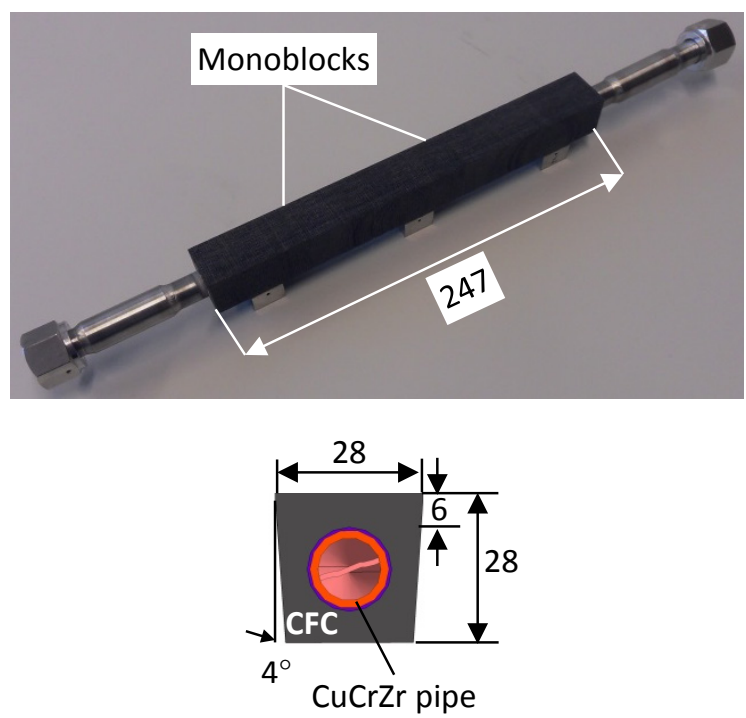

Fig. 1. Picture of a PFC prototype (unit in $\mathrm{mm}$ )

Fig. 2 shows the twisted tape made of copper, $1 \mathrm{~mm}$ thick and twist ratio of 2, positioned inside the cooling pipe. The twist ratio defines the length to diameter ratio for one $180^{\circ}$ twist. The tape is mechanically attached with nuts machined in the stainless steel part. The tape function is to enhance the heat transfer of forced convection in the single phase regime and the margin to critical heat flux.

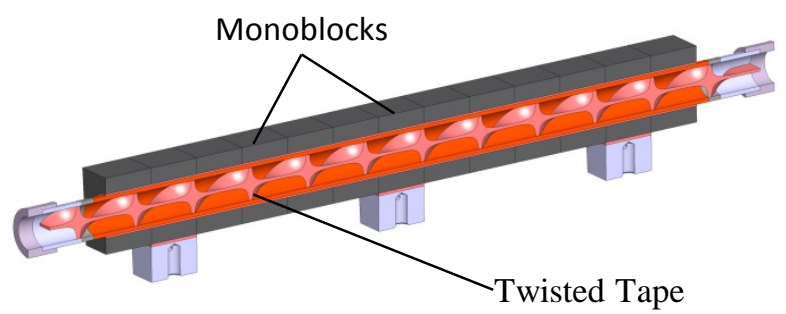

Fig. 2. Cross view of PFC prototype

The delivered elements passed the helium leak tightness test in the dedicated oven. The acceptance criteria are the same as for the $\mathrm{W} 7-\mathrm{X}$ divertor target elements [8]: a leak rate lower than $5.10^{-7} \mathrm{~Pa} \mathrm{l} / \mathrm{s}$ at room temperature and 3.2MPa internal He pressure, and a leak rate lower than $5.10^{-6} \mathrm{~Pa} \mathrm{l} / \mathrm{s}$ at $160^{\circ} \mathrm{C}$ and $2.5 \mathrm{MPa}$ internal He pressure.

\section{High heat flux test campaign}

The high heat flux test campaign was carried out in the GLADIS test facility [9], which generates a loading distribution with a Gaussian profile. The PFC prototypes were placed normal to the beam axis in the vacuum chamber of the facility. The element was positioned outside the chamber onto the dedicated support frame and moved into the chamber with the manipulator of the vacuum lock system (aperture on the right side). The element was water cooled at an axial velocity of $12 \mathrm{~m} / \mathrm{s}$ at room temperature. The static pressure was $1 \mathrm{MPa}$. The prototypes Nr. 2, 3, 7 and 8 were loaded. For each prototype, two positions were tested: beam centered on monoblocks Nr. 5 and on Nr. 9. The duty cycle was $15 \mathrm{~s}$. on and $75 \mathrm{~s}$. off.

The testing campaign of each prototype was divided into the screening test (10 cycles at $10 \mathrm{MW} / \mathrm{m}^{2}, 10$ cycles at $15 \mathrm{MW} / \mathrm{m}^{2}$, and 10 cycles at $20 \mathrm{MW} / \mathrm{m}^{2}$ ) followed by the cycling test of 90 cycles at $20 \mathrm{MW} / \mathrm{m}^{2}$. Fig. 3 and 4 show the surface temperature distribution in the visible and infrared ranges, respectively, of the Nr. 8 prototype at the end of the testing at $20 \mathrm{MW} / \mathrm{m}^{2}$. The beam is centered on the monoblock Nr. 9. The vertical dimension of the loaded surface is $28 \mathrm{~mm}$.

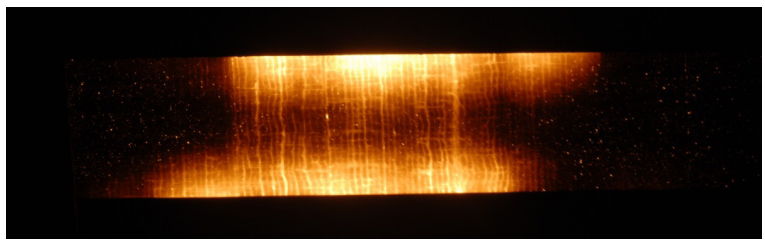

Fig. 3. CCD picture of the loaded surface of prototype \# 8 at $20 \mathrm{MW} / \mathrm{m}^{2}$.

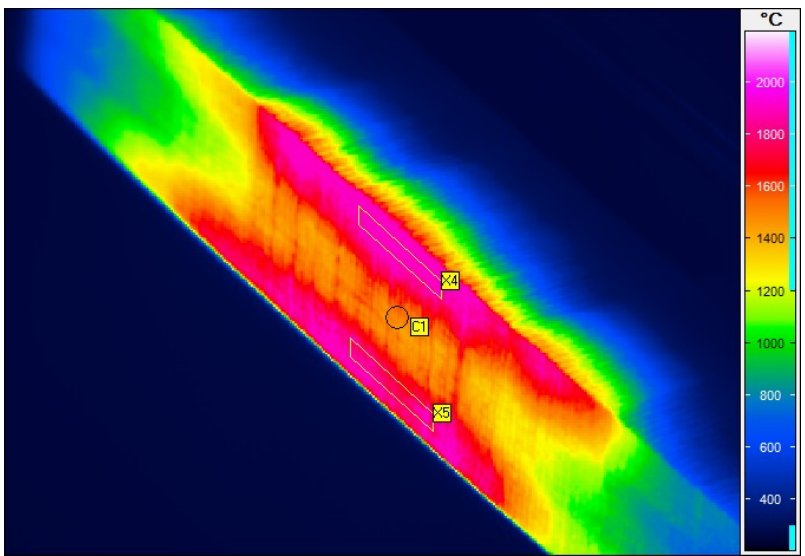

Fig. 4: Infrared picture of the loaded surface of prototype \# 8 at $20 \mathrm{MW} / \mathrm{m}^{2}$.

Due to the monoblock geometry (Fig. 1), the surface temperature at the center is obviously lower than at the edges. No initiation of hot spots at the surface or degradation of the monoblock cooling down between consecutive pulses in GLADIS for any tested prototype was detected. This observation indicates the reliability of the bonding between CFC monoblocks and cooling channel. 
Fig. 5 and 6 compare the calculated and measured surface temperatures at the centre and at the outer edges of the monoblocks, respectively. Calculations were performed with ANSYS taking the materials property dependence on temperature into account. The heat transfer coefficient at the wall of the cooling channel is calculated for the forced convective and sub-cooled nucleate boiling regimes. Another approach is the modeling of the water effects in single flow [10]. The measured surface temperatures were monitored from the infrared cameras as an average value at the surface of circle $\mathrm{C} 1$ for the centre and bands X1 (upper edge) and $\mathrm{X} 4$ (lower edge) for the edges (Fig. 4). The raw infrared measured temperatures were corrected taken into account an CFC emissivity of 0.8 .

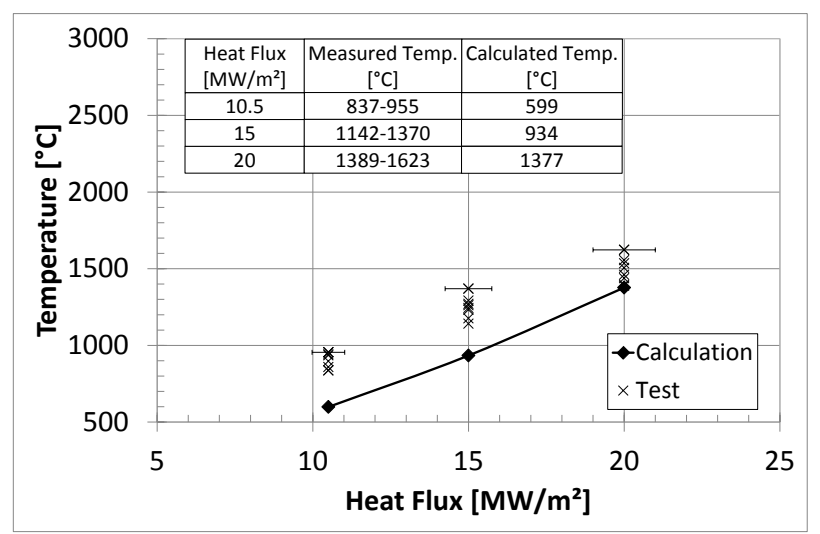

Fig. 5. Comparison between calculated and measured surface temperatures at the centre of the element for all prototypes. Error bars for the heat flux are $\pm 5 \%$.

At the central position and at the edges, measurements are higher than calculations.. The scattering of the measured values for the different heat fluxes and positions is within the acceptable range of $\pm 10 \%$ due to the inherent CFC inhomogeneity. The temperatures at the edges for $20 \mathrm{MW} / \mathrm{m}^{2}$ exceeds the measurement range $\leq 2000^{\circ} \mathrm{C}$ of the IR camera. The reason for the difference between calculations and measurements is the local inhomogeneity of the CFC material properties, which results in a reduced local thermal conductivity.

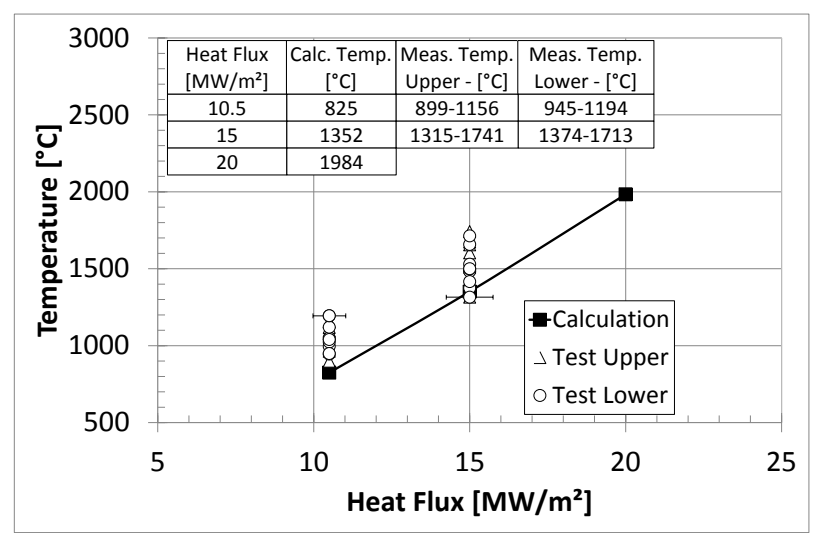

Fig. 6. Comparison between calculated and measured surface temperatures at the edges of the element for all prototypes. Error bars for the heat flux are $\pm 5 \%$.
This effect has been detected by a difference higher than $300^{\circ} \mathrm{C}$ between lower and upper edges of some monoblocks. This local variation of the thermal conductivity cannot be taken into account by calculations and explains this difference.

\section{Water box prototype}

The integration of the scraper element inside the machine requires a very compact design of the cooling system [11]. In each scraper module, the water boxes made of stainless steel are the hydraulic connection between 4 PFCs cooled at high velocities in series. The fabrication of the prototypes was awarded to the company Dockweiler. The design of the completed prototype is shown in Fig. 7: 4 PFCs connected to 2 water boxes. The jigs for testing are not shown.

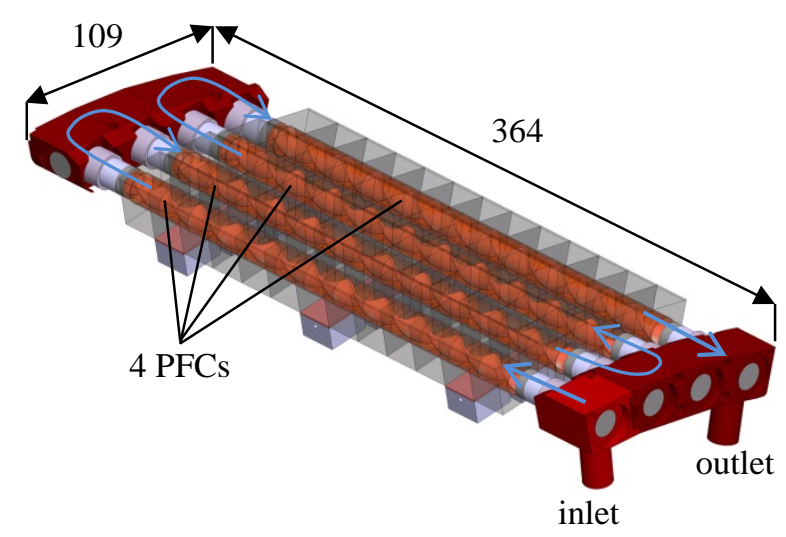

Fig. 7. Scraper module prototype (unit in $\mathrm{mm}$ ). The blue lines indicate the water direction.

The main difficulty is to achieve a reliable connection between the PFC cooling tube and the water boxes. The selected approach is to perform this join by TIG orbital welding from the inside. This technology has been successfully used for the manifolds of the cooling circuit of the first wall and for the manifolds of the high heat flux divertor in W7-X [12]. The apertures in the boxes on the opposite side of each PFC connection have been dimensioned to allow the installation and positioning of the welding tools as well as the visual inspection of the welds with videoscope (Fig. 6). The thickness of the caps to close the boxes is $2 \mathrm{~mm}$. In addition apertures have been designed on the side to allow the machining of the cooling channel inside the box. The water direction in the water boxes is shown in Fig. 7. One box is made of one piece because the separation is in the centre part of the box; the channel is machined from both sides. For the inlet/outlet box, two separations are needed to define the cooling circuit. The only possibility is to split this box into two parts, and then welded them together. A first prototype of this part is also shown in Fig. 8. 


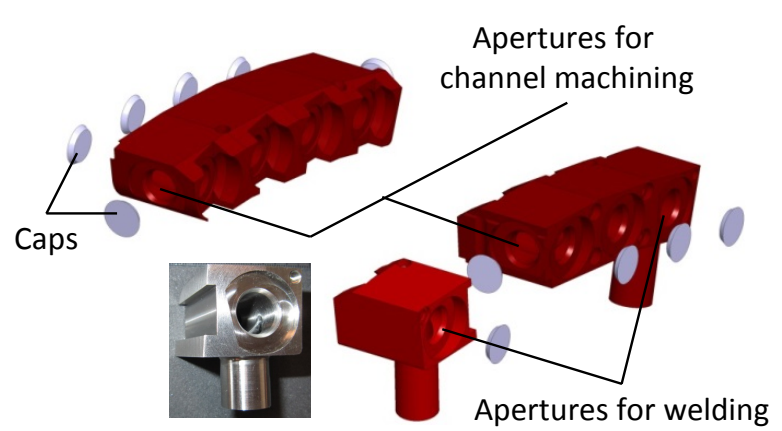

Fig. 9. Prototype for water boxes (picture: Courtesy of Dockweiler)

The full-scale prototype of the water boxes is presently under production. Before the fabrication of this module prototype, an intermediate prototype will be produced to validate the presented manufacturing process of the water boxes in which the PFCs are replaced by stainless steel tubes to avoid possibly damaging of the PFCs at this stage [13]. Once possibly improved and qualified, the module prototype will be fabricated using the 4 remaining PFC prototypes and tested in the GLADIS facility.

\section{Conclusion}

The water-cooled scraper element has been designed to shield the ends of the actively cooled divertor targets against excessive localized heat fluxes. Due to the restricted available space, its design has to be very compact and allow the removal of localized heat fluxes as high as $20 \mathrm{MW} / \mathrm{m}^{2}$ in steady state conditions.

The high heat flux test campaign performed in GLADIS on 4 PFC prototypes confirmed that the monoblock technology is suitable to remove the calculated high thermal loads. The reason for the difference between calculated and measured surface temperatures is the local inhomogeneity of the CFC thermal conductivity.

The on-going activities on the fabrication of the water box prototypes are very promising. Some changes in the preliminary design have been required to adapt the orbital welding technology to their compact design. The present work focuses on developing reliable and verifiable welds between the PFCs and the water boxes. Once this technology is validated by different inspections followed by a test campaign in GLADIS, the possible improvement of hydraulics in the water boxes will be studied. The achieved results on these prototypes improve the technological basis for a possible manufacturing and installation of the water-cooled scraper element for the full long pulse operation of W7$\mathrm{X}$.

\section{Acknowledgements}

This work was supported by the Federal Ministry of Education and Research of the Federal Republic of Germany under Grant 03FUS0014A. Only the authors are responsible for the content of this publication.

\section{References}

[1] M. Gasparotto, C. Baylard, H.S. Bosch, D. Hartmann, T. Klinger, R. Vilbrandt, et al., Wendelstein 7-X - Status of the project and commissioning planning, Fusion Eng. Des. 89 (2014) pp. 2121-2127.

[2] A. Peacock, H. Greuner, F. Hurd, J. Kißlinger, R. König, B. Mendelevitch, et al., Progress in the design and development of a test divertor (TDU) for the start of W7-X operation, Fusion Eng. Des. 84 (2009) pp. 1475-1478.

[3] J. Boscary, A. Peacock, T. Friedrich, H. Greuner, B. Böswirth, H. Tittes, et al., Design improvement of the target elements of Wendelstein 7-X divertor, Fusion Eng. Des. 87 (2012) pp. 1453-1456.

[4] J. Lore, T. Andreeva, J. Boscary, S. Bozhenkov, J. Geiger, J. Harris, et al., Design and analysis of divertor scraper elements for the W7-X stellarator, IEEE Trans. on Plasma Sci. 42 (3) (2014) pp. 539-544.

[5] A. Lumsdaine, J. Boscary, J. Fellinger, J. Harris, H. Hölbe, R. König, , et al., Design of the Wendelstein 7-X inertially cooled Test Divertor Unit Scraper Element, Fusion Eng. Des. 98-99 (2015) pp. 1357-1361.

[6] M. Richou, M. Missirlian, B. Riccardi, P. Gavila, C. Desgranges, N. Vignal, et al., Assessment of CFC grades under thermal fatigue for the ITER inner vertical target, Phys. Scr. T145 (2011).

[7] H Traxler, P Schuler, Pulsed thermography inspection of the target elements for the W7-X divertor, Phys. Scr. T128 (2007) pp. 242-245.

[8] J. Boscary, B. Böswirth, H. Greuner, P. Grigull, M. Missirlian, A. Plankensteiner, et al., Fabrication and testing of W7-X pre-series target elements, Phys. Scripta T128 (2007) pp. 195-199.

[9] H. Greuner, ,H. Bolt, B. Böswirth, T. Franke, P. McNeely, S. Obermayer, et al., Design, performance and construction of a $2 \mathrm{MW}$ ion beam test facility for plasma facing components, Fusion Eng. Des. 75-79 (2005) pp. 345-350.

[10] E. Clark, K. Ekici, A. Lumsdaine, C. Barbier, J. Harris, et al., Thermal-fluid modeling of single- and two-phase flows in the W7-X high heat flux divertor scraper element, 26th IEEE Symposium on Fusion Engineering (SOFE 2015), Austin, TX. 2015-05-31 - 2015-06-04.

[11] A. Lumsdaine, T. Bjorholm, J. Harris, D. McGinnis, J.D. Lore, J. Boscary, et al., Overview of Design and Analysis Activities for the W7-X Scraper Element, IEEE Trans. on Plasma Science, in press.

[12] B. Mendelevitch, A. Vorköper, J. Boscary, A. Cardella, F. Hurd, Ch. Li, et al., Design analysis and manufacturing of the cooling lines of the in vessel components of W7-X, Fusion Eng. Des. 86 (2011) pp. 1669-1672.

[13] J. Boscary, J. Lore, A. Lumsdaine, M. Maier, D. McGinnis, A. Peacock, et al., Development activities of the high heat flux scraper element, Fusion Eng. Des. 9899 (2015) pp. 1231-1234. 